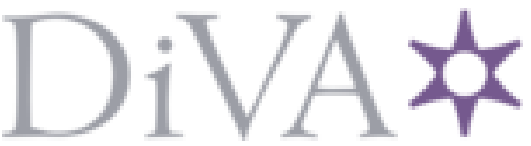

http://www.diva-portal.org

\title{
Postprint
}

This is the accepted version of a paper presented at ISGT-Europe 2021 : IEEE PES Innovative Smart Grid Technologies Conference Europe, Espoo, Oct 26, 2021.

Citation for the original published paper:

Jiao, Y., Månsson, D. (2021)

Power Distribution Strategy Based on Low-PassFilter Controller with a Variable Time Constant in Hybrid Energy Storage Systems

In: Power Distribution Strategy Based on Low-PassFilter Controller with a Variable Time Constant in Hybrid Energy Storage Systems

N.B. When citing this work, cite the original published paper.

Permanent link to this version:

http://urn.kb.se/resolve?urn=urn:nbn:se:kth:diva-305969 


\section{Power Distribution Strategy Based on Low-Pass Filter Controller with a Variable Time Constant in Hybrid Energy Storage Systems}

\author{
Yang Jiao \\ Division of Electromagnetic Engineering \\ KTH Royal Institute of Technology \\ Stockholm, Sweden \\ yjiao@kth.se
}

\author{
Daniel Månsson \\ Division of Electromagnetic Engineering \\ KTH Royal Institute of Technology \\ Stockholm, Sweden \\ manssond@kth.se
}

\begin{abstract}
A critical issue in a hybrid energy storage system (HESS) is the control strategy, especially the power distribution between the individual energy storage devices. In this paper, the power distribution strategy based on the low-pass filter (LPF) controller with a variable time constant is introduced. The adjustable range of the variable time constant is determined by the spectrum analysis of the imbalanced power in a stand-alone household-prosumer system. In addition, the variation of the time constant is based on the feedback of the state of charge (SoC) of the supercapacitor (SC). The simulation results show that the power distribution strategy keeps the SoC of the $\mathrm{SC}$ in a moderate range and utilizes the $\mathrm{SC}$ more properly. A scaleddown experimental setup is built to verify the effectiveness of the power distribution strategy and the simulation results. Therefore, the proposed power distribution strategy ensures the effective operation of the HESS, avoids the unnecessary enlarging of the $\mathrm{SC}$, and achieves cost reduction.
\end{abstract}

Keywords-Household-prosumer, hybrid energy storage system (HESS), variable time constant, state of charge (SoC).

\section{INTRODUCTION}

Energy storage devices can be classified into two broad types: high energy density and high power density [1]. Due to the limitation of energy storage technologies, it is difficult for a single energy storage device to meet the requirements of systems that contain renewable energy sources (RESs) [2]. However, hybrid energy storage systems (HESSs), which are the combination of two or more energy storage technologies, can take full advantage of complementary characteristics of the energy storage deceives, such as batteries and supercapacitors (SCs) [3].

One of the most important problems in the HESS is the control strategy used to handle the power distribution within the HESSs [4]. The key factor of the power distribution to consider is obtaining the respective charging and discharging powers for the two energy storage devices based on their characteristics. A large and growing body of literature has investigated the power distribution between the individual energy storage devices of HESSs. The vast majority of studies focus on the low-pass filtering method to distribute the power for each energy storage device [5][6]. For example, the battery handles the low frequency power and the $\mathrm{SC}$ is responsible for the high frequency power. However, it does not consider the power limit of the battery and the state of charge (SoC) of the SC. In literature [7], the power distribution in HESSs is determined by the SoC of the SC, which ensures that the SoC of the SC is within a safe range. In addition, several studies have reported using a variable time constant in the low-pass

This work was supported in part by the China Scholarship Council (CSC) and KTH Royal Institute of Technology, and in part by the StandUp for Energy project via the Swedish Research Council. filter (LPF) to determine the distribution of the power demand for the HESS [8]. This reduces the required capacity of the HESS. Nonetheless, the research to date has not been able to satisfactorily combine the $\mathrm{SoC}$ control with a variable time constant in the LPF controller and conduct an in-depth analysis of the capacity ratio of the two energy storage devices in HESSs.

In this paper, based on the LPF controller with a variable time constant, the power distribution strategy of battery-SC HESSs is proposed for a household-prosumer system utilizing photovoltaic (PV) power. The relationship between the SoC of the SC and the variable time constant is established. The simulation and experimental results show that with a fixed time constant in the LPF controller, the capacity of the installed SC cannot meet the capacity requirement placed upon the SC. However, when the power distribution strategy is used, the installed SC fulfills the capacity requirement. The power distribution strategy is able to make better use of the $\mathrm{SC}$ to realize the complementary characteristics of the two energy storage devices because it modifies the SoC of the SC to a moderate $\mathrm{SoC}$ value. Therefore, the power distribution strategy ensures the effective operation of the HESS and avoids the unnecessary enlarging of the SC. As a result, the cost of the HESS is reduced. This paper is organized as follows: Section I is the introduction. Section II describes the proposed power distribution strategy of the HESS. The simulation results are given in Section III. The experimental results are presented in Section IV. Finally, the conclusions are summarized in Section V.

\section{Power Distribution Strategy OF Hybrid ENERGy STORAGE SYSTEM}

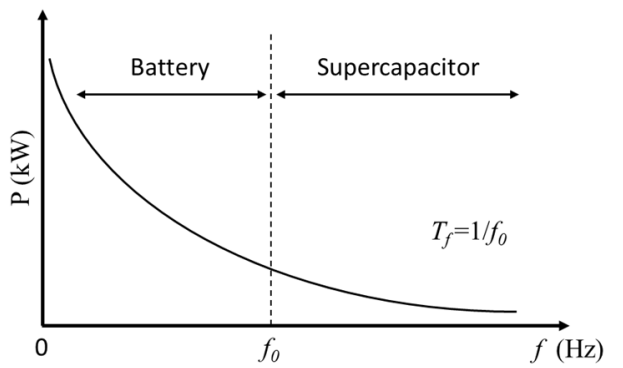

Fig. 1. Schematic diagram of the spectrum for the HESS power in a household-prosumer system.

In a RES household-prosumer system, the power demand placed on the HESS is the difference between the output of the RES and the load curve. The HESS, thus, regulates mismatches by storing excess energy and supplying the load when demanded. To determine the time scale of the power 
demand that the HESS needs to handle, the Fast Fourier Transform (FFT) analysis is performed on the imbalanced power in the system [9]. The frequency spectrum for the HESS power reflects the amplitude of the power flow at different frequencies, which is shown in Fig.1.

As can be seen from the spectrum, the amplitude of the power demand decreases with increasing frequency. Therefore, the required capacity of the energy storage device to compensate for the low frequency power components is relatively large, while the capacity of the energy storage device needed to compensate for the high frequency power components is relatively small [10]. As a result, it is reasonable to use batteries to handle the low frequency power as batteries have high energy density and relatively low cost compared with SCs. Meanwhile, SCs are responsible for the high frequency power due to their high power density and long cycle lifetime. Then, the LPF method is used to split the frequency of the power demand and determine the necessary power distribution between the battery and the SC. Lastly, the relevant time constant in the LPF controller is determined from the cut-off frequency.

However, the deficiency is that the impact on the chargedischarge control from the different SoC of the individual energy storage devices is not considered. This is especially problematic for the SC having a high cost. In addition, when the SoC of the SC exceeds its limit, the operation of the HESS might be disrupted and there is only the battery to handle the imbalanced power in the system. Therefore, the variable time constant based on the feedback of the SoC of the SC is utilized to adjust the power distribution and enable the HESS to achieve cost reduction and long-term effective operation.

To adjust the power distribution, the adjustable range of the SoC of the SC is here, as shown in Table I, divided into five intervals. The $S o C_{\max }$ and $S o C_{\min }$ are the SoC limits of the $\mathrm{SC}$, thus, the SoC interval $a$ and interval $e$ are unavailable for the SC. When the SoC state is in interval $c$, the SoC of the SC is in the middle interval and the power demand is split by the LPF with the default value. When the SoC is in interval $b$, the $\mathrm{SC}$ is in the low SoC state. Therefore, the power distribution should increase the SC power flow when it is being charged $\left(I_{S C}<0\right)$ and decrease the SC power flow when it is being discharged $\left(I_{S C}>0\right)$. When the SoC is in interval $d$, to avoid overcharging the $\mathrm{SC}$ and enter interval $e$, the $\mathrm{SC}$ is adjusted to discharge to the maximum extent and limits the charging power of the SC. Therefore, the SC is able to return to the normal working state as soon as possible. In addition, to realize this charge-discharge control, the relevant variation of the time constant $T_{f}$ is listed in the table. The flowchart for adjusting the variable time constant is shown in Fig. 2.

As shown in Fig. 3, the time constant in the LPF controller is adjusted by the SoC of the SC for the five intervals. The power demand for the HESS $P_{\text {demand }}$ is split into low frequency

TABLE I

SOC INTERVAL DIVISION AND CHARGE-DISCHARGE CONTROL FOR THE SC

\begin{tabular}{|c|c|c|c|c|c|}
\hline Interval & $a$ & $b$ & $c$ & $d$ & $e$ \\
\hline SoC range of SC & {$\left[0, S o C_{\min }\right]$} & {$\left[S o C_{\min }, S o C_{l o w}\right]$} & {$\left[S o C_{l o w}, S o C_{h i g h}\right]$} & {$\left[S o C_{h i g h}, S o C_{\max }\right]$} & {$\left[S o C_{\max }, 1\right]$} \\
\hline $\begin{array}{l}\text { Charge-discharge } \\
\text { control }\end{array}$ & $\begin{array}{l}\text { Only charge for } \\
\text { protection }\end{array}$ & $\begin{array}{l}\text { Increasing charge } \\
\text { Reducing discharge }\end{array}$ & $\begin{array}{l}\text { Default charge and } \\
\text { discharge }\end{array}$ & $\begin{array}{l}\text { Reducing charge } \\
\text { Increasing discharge }\end{array}$ & $\begin{array}{l}\text { Only discharge for } \\
\text { protection }\end{array}$ \\
\hline Variation of $T_{f}$ & $\begin{array}{c}\text { Charge: } T_{f_{-} \max } \\
\text { Discharge: } T_{f_{-} \min }\end{array}$ & $\begin{array}{c}\text { Charge: increasing } T_{f} \\
\text { Discharge: decreasing } T_{f}\end{array}$ & Default $T_{f_{-} 0}$ & $\begin{array}{c}\text { Charge: decreasing } T_{f} \\
\text { Discharge: increasing } T_{f}\end{array}$ & $\begin{array}{c}\text { Charge: } T_{f_{-} \min } \\
\text { Discharge: } T_{f_{-} \max }\end{array}$ \\
\hline
\end{tabular}

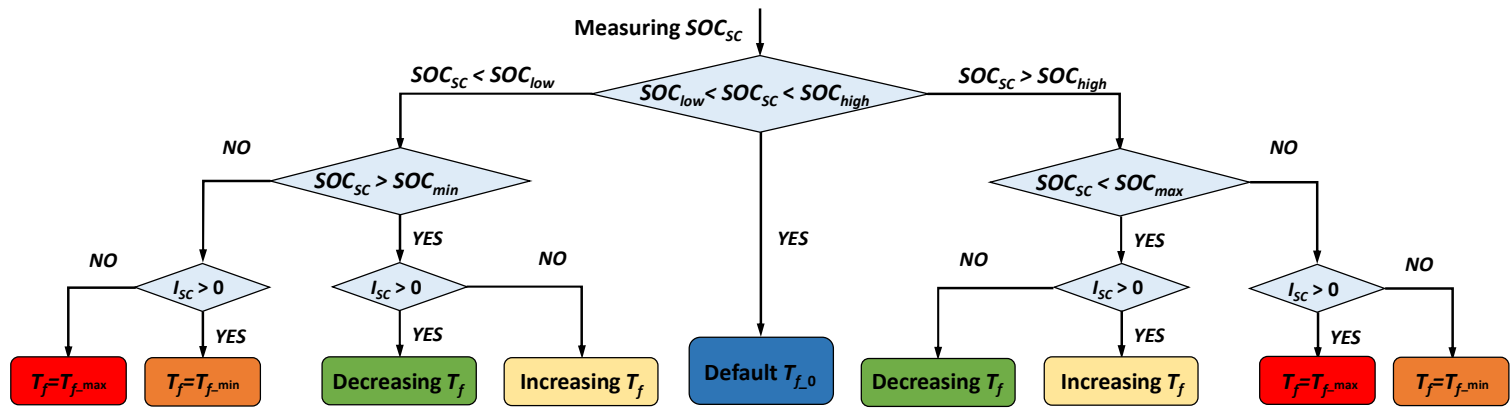

Fig. 2. Flowchart of the strategy for adjusting the variable time constant.

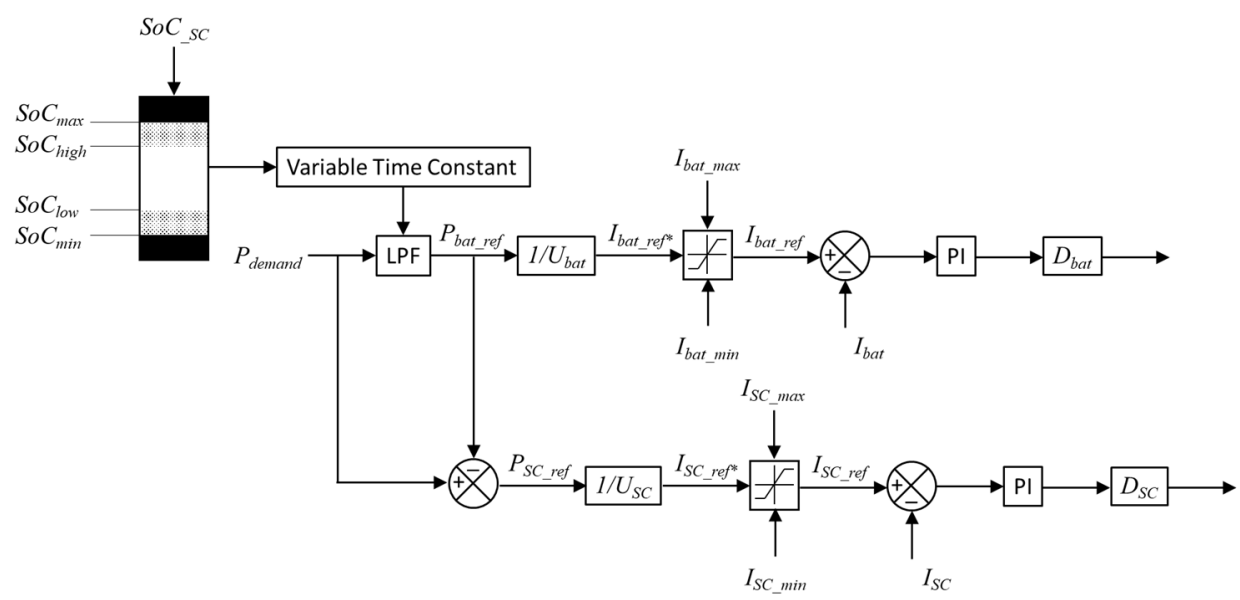

Fig. 3. Control strategy of the HESS based on a variable time constant. 
components and high frequency components by the LPF. The reference power $P_{\text {bat_ref }}$ of the battery is divided by the voltage of the battery $U_{b a t}$ to obtain the reference current $I_{b a t}$ ref*. To avoid damage to the battery caused by the overcurrent, $I_{b a t}$ ref* $^{*}$ is limited to the safe range (between the upper limit and the lower limit). Then, the difference between $I_{b a t}$ ref and the actual battery current $I_{b a t}$ is transformed by the PI controller to the duty cycle $D_{b a t}$, which controls the DC/DC converter of the battery. The same control flow is applied to the SC. In addition, to avoid overcharging and overdischarging of the energy storage devices, the energy storage devices stop the relevant charging/discharging when they reach the upper and lower voltage limits.

Based on the charge-discharge strategy mentioned above, the relationship between the time constant $T_{f}$ and the SoC of the SC is established, as shown in Fig. 4. $T_{f}$ charge shows the relationship between $T_{f}$ and the SoC of the SC in the charging state and $T_{f}$ discharge shows the relationship between $T_{f}$ and the $\mathrm{SoC}$ of the $\mathrm{SC}$ in the discharging state. The charging and discharging power of the $\mathrm{SC}$ increases with increasing $T_{f}$ because the battery handles less power under the narrow frequency band. Conversely, the power of the SC decreases with decreasing $T_{f}$. The variable time constant directly adjusts the charging and discharging power of the SC. Thus, the SoC of the SC is modified back to the middle interval.

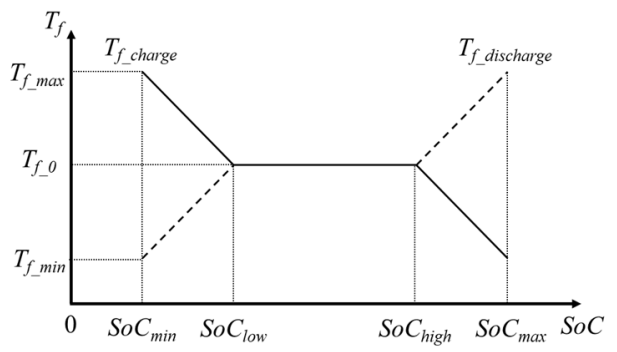

Fig. 4. Relationship between the time constant $T_{f}$ in the LPF controller and the SoC of the SC.

In the figure, the SoC segmental points depend on the characteristics of the energy storage technology. For most $\mathrm{SCs}$, the available voltage is from zero to its rated voltage. However, the available voltage of SCs is limited by the operation voltage of the DC/DC converter. In addition, $T_{f} 0$ corresponds to the SoC of the SC in the middle interval. Most of the time, the HESS is controlled by this time constant value.

\section{Simulation CASE STUdY}

To illustrate the performance of the here proposed variable time constant LPF controller, the analysis of the power flows and SoC of the energy storage devices in the HESS is presented for a 24 hours simulation. The HESS is controlled by the LPF controller with a fixed $T_{f}$ and a variable $T_{f}$, respectively.

In the simulation, the household-prosumer system contains a PV array and a household load. The PV output data contained in this paper is collected from a $2.4 \mathrm{~kW}$ PV array [11]. The load power data are from a household electricity demand dataset in the UK [12]. The PV power and the load power of the stand-alone system for 24 hours are shown in Fig. 5. The power flow in the DC bus that needs to be handled by the HESS, $P_{\text {demand }}$, is the difference between the PV power $P_{P V}$ and the load power:

$$
P_{\text {demand }}=P_{P V}-P_{\text {load }}
$$

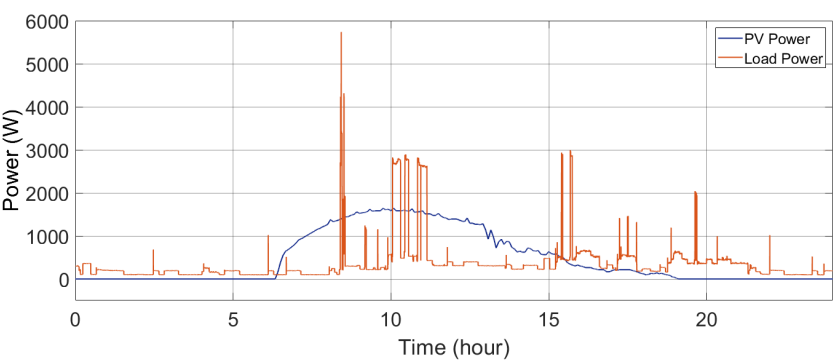

Fig. 5. PV power and load power of the household-prosumer system for 24 hours.

In addition, a battery pack with $10 \mathrm{kWh}$ capacity and a SC pack with $0.4 \mathrm{kWh}$ capacity are used to build the HESS for the analysis. The available SoC of the battery is from $20 \%$ to $90 \%$ [13] and the available SoC of the SC is from $16 \%$ to $100 \%$ $\left(V_{S C_{-} \min }=0.4 V_{S_{-} \max }\right)[14]$, respectively.

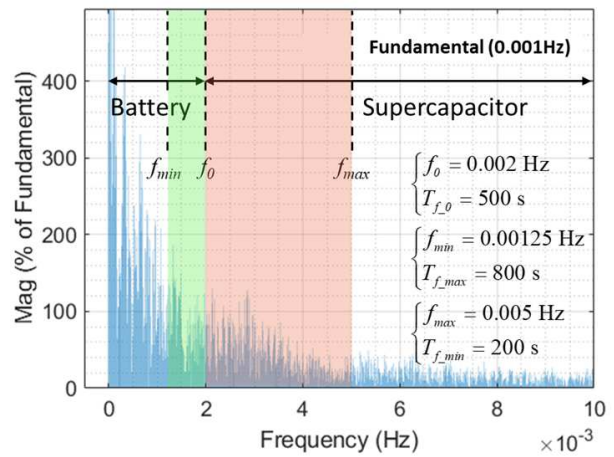

Fig. 6. FFT analysis of the power demand for the HESS.

The FFT analysis is applied to the power demand handled by the HESS, as shown in Fig. 6. The default cut-off frequency of the LPF controller is chosen to be $0.002 \mathrm{~Hz}$ (i.e., $\mathrm{T}_{f_{-}}=500 \mathrm{~s}$ ) because the high frequency components are concentrated in the band between $0.002 \mathrm{~Hz}$ to $0.01 \mathrm{~Hz}$. The power in the low frequency band is managed by the battery and the high frequency power is managed by the SC. According to the SoC of the SC, the cut-off frequency point where the SC takes over from the battery can be adjusted from $0.00125 \mathrm{~Hz}$ to $0.005 \mathrm{~Hz}$.

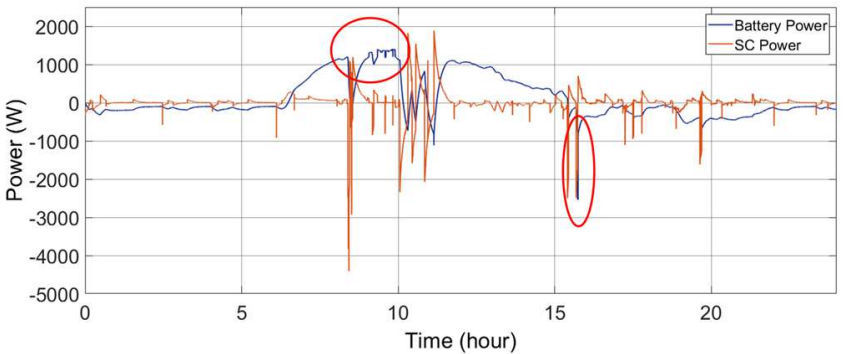

(a)

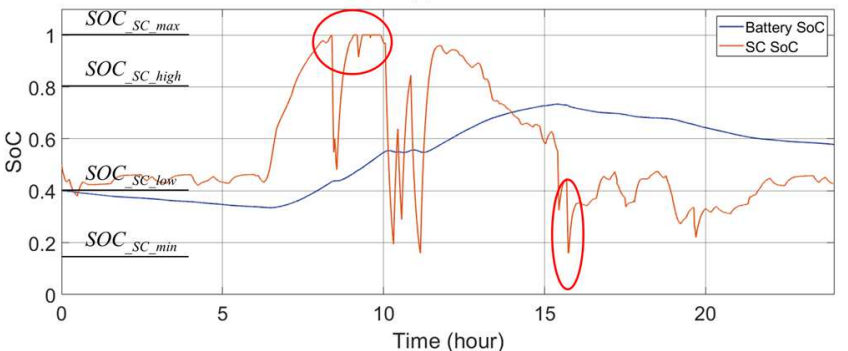

(b)

Fig. 7. Power flows and SoC of energy storage devices in the HESS that is controlled by the LPF controller with a fixed time constant $T_{f}$ : (a) Power flows of the battery and the SC. (b) SoC of the battery and the SC. 
The power flows of the battery and the SC are shown in Fig. 7(a) for a fixed time constant $\left(T_{f}=500 \mathrm{~s}\right)$. It can be seen that the battery only handles the low frequency components of the power demand, while the SC manages the high frequency power components. The SC charges and discharges more frequently than the battery as well as having more changes in the state. Also, as shown in Fig. 7(b), the SoC of the SC reaches its upper and lower limits during the simulation. As marked in the red circles, the SC is turned off for some time intervals to avoid that the SC exceeds the limits. Therefore, during these time intervals, only the battery is available to handle the whole power demand. To ensure the operation of the HESS, the capacity of the SC needs to be increased.

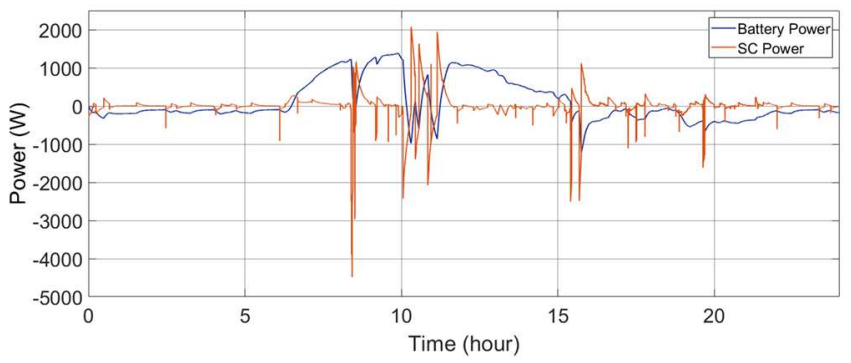

(a)

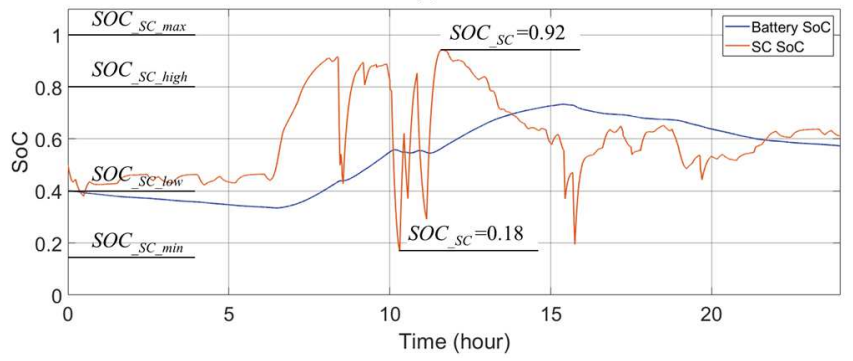

(b)

Fig. 8. Power flows and SoC of energy storage devices in a HESS that is controlled by the LPF controller with a variable time constant $T_{f}$ : (a) Power flows of the battery and the SC. (b) SoC of the battery and the SC.

Fig. 8 shows the power flows and SoC of the energy storage devices in a HESS that is controlled by the LPF controller with a variable $T_{f}$. Similar to the LPF controller with fixed $T_{f}$, the controller with a variable $T_{f}$ effectively splits the power demand into two parts. The SC responds to the high frequency power components and reduces the stress of the battery. By using a variable $T_{f}$, the SoC of the SC is between 0.18 and 0.92 during the test. Thus, the SC operates within the available SoC range, instead of exceeding the limits (which happens for the HESS with a fixed time constant). Meanwhile, the $\mathrm{SoC}$ of the battery is almost the same as in the previous case. Thus, the required capacity of the $\mathrm{SC}$ is reduced without affecting the required battery capacity. The results indicate the effectiveness of the power distribution strategy based on the LPF controller with a variable time constant.

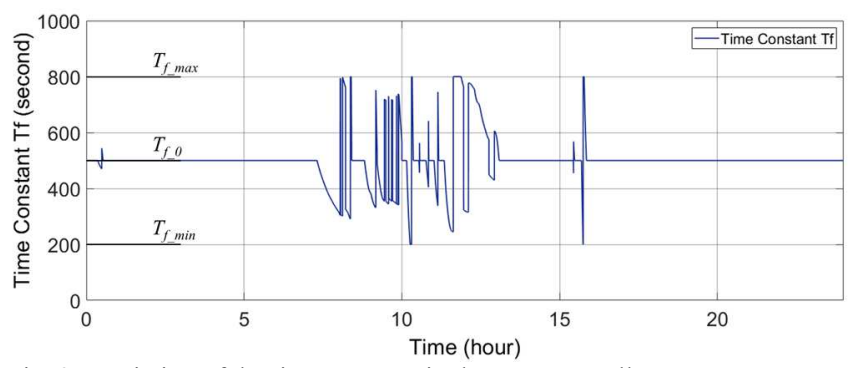

Fig. 9. Variation of the time constant in the LPF controller.
The variation of the time constant in the LPF controller based on the SoC of the $\mathrm{SC}$ is shown in Fig. 9. When the SoC of the SC is lower than $40 \%$ or larger than $80 \%$, the $T_{f}$ is adjusted to modify the SoC of the SC back to the safe range. In addition, the $T_{f}$ is kept as a constant, at the default value, when the SC operates in the middle interval of SoC.

The power distribution strategy utilizes the capacity of the SC more properly because the variable $T_{f}$ modifies the SoC of the $\mathrm{SC}$ to the moderate $\mathrm{SoC}$ range. Controlled by the proposed power distribution strategy, although the SC has the same capacity as the case when the SC is controlled by a fixed time constant value, the SC is able to meet the power demand during the whole testing. Therefore, the proposed power distribution strategy ensures the effective operation of the HESS, avoids the unnecessary enlarging of the SC, and achieves cost reduction.

\section{EXPERIMENT VERIFICATION}

The power distribution strategy and the performance of the HESS have been verified using a scaled-down experimental setup, as shown in Fig. 10. A regulated power supply is used as a PV generator. The household load profiles are emulated by a DC electronic load. The HESS consists of a Li-ion battery and a SC bank. The bi-directional DC/DC converter is made up of two MOSFETs, two capacitors, and an inductor using the half-bridge topology. The nominal parameters of the experimental devices are given in Table II.

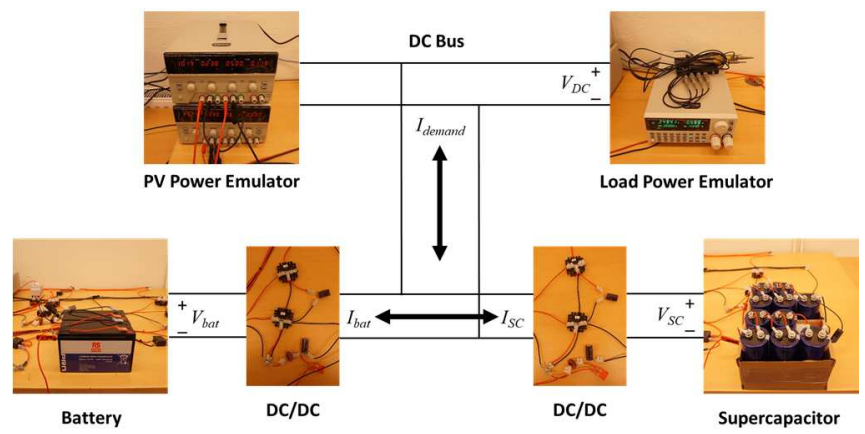

Fig. 10. HESS experimental setup.

TABLE II

NOMINAL PARAMETERS OF THE EXPERIMENTAL DEVICES

\begin{tabular}{c|l}
\hline \multicolumn{2}{c}{ NOMINAL PARAMETERS OF THE EXPERIMENTAL DEVICES } \\
\hline Devices & Specifications \\
\hline DC Bus & $V_{D C}=25 \mathrm{~V} \pm 5 \%$ \\
\hline $\begin{array}{c}\text { PV Power } \\
\text { emulator }\end{array}$ & $\begin{array}{l}\text { Programmable power supply: } \\
\text { RND 320-KD3305P [15], }\end{array}$ \\
\hline $\begin{array}{c}\text { Load Power } \\
\text { emulator }\end{array}$ & $\begin{array}{l}\text { Programmable DC electronic load: } \\
\text { RND 320-KEL102 [16] }\end{array}$ \\
\hline $\begin{array}{c}\text { Battery } \\
\text { cell }\end{array}$ & 12.8 V/7.5 Ah, \\
\hline $\begin{array}{c}\text { Supercapacitor } \\
\text { cell }\end{array}$ & $\begin{array}{l}\text { 2400 F/2.7 V, }, \\
\text { RND Radial Super Capacitor [18] }\end{array}$ \\
\hline DC/DC & $\begin{array}{l}\text { MOSFET: IRL2505PBF - MOSFET N [19], } \\
\text { converter }\end{array}$ \\
& $C=1000 \mathrm{uF}, L=174 \mathrm{uH}$ \\
\hline
\end{tabular}

In this scaled-down setup, the power demand for the HESS is reduced to one-twentieth of the original PV power and load power demand data [11] [12]. The measured currents of the battery and the SC are shown in Fig. 11. Both the LPF controllers (fixed $T_{f}$ vs. variable $T_{f}$ ) are able to split the power demand. The SCs are controlled to manage most of the high frequency components in the demand. In addition, the 
comparison of the SoC of the SCs is shown in Fig. 12. The experimental results show that the $\mathrm{SoC}$ of the $\mathrm{SC}$ reaches the upper limit when the fixed $T_{f}$ is set as 500 seconds, which is similar to the simulation results (reaching both the upper and lower limits). As shown in Zoom In I in Fig. 11(a), during this time interval, the SC is turned off and the battery current is not smooth. However, when a variable $T_{f}$ is used in the LPF controller, the SoC of the SC stays in the available SoC range during the whole test and handles the power peaks. Therefore, the battery current is smooth (e.g., Zoom In I in Fig. 11(b)) during the whole testing. Moreover, as shown in Zoom In II in fig. 11(b), compared to Fig. 11(a), if the SoC of the SC is too low, the $\mathrm{SC}$ is charged with a larger current and returns to the moderate $\mathrm{SoC}$ value when the time constant is variable. As a result, although the capacities of the SCs are the same in these two cases, the SC is operated more properly for its available capacity if a variable time constant is used.

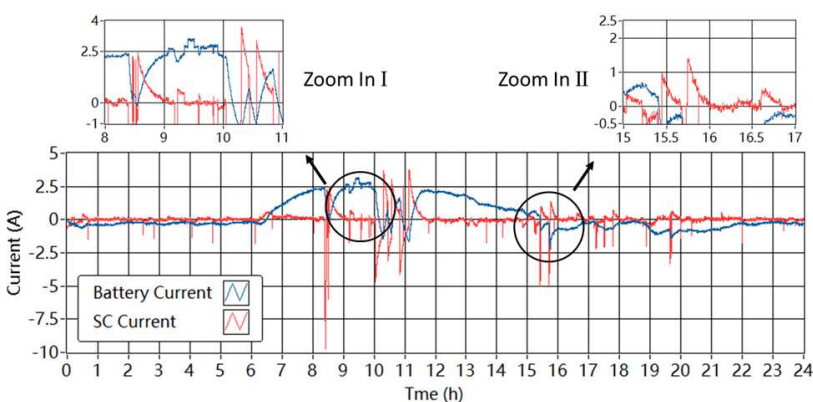

(a)

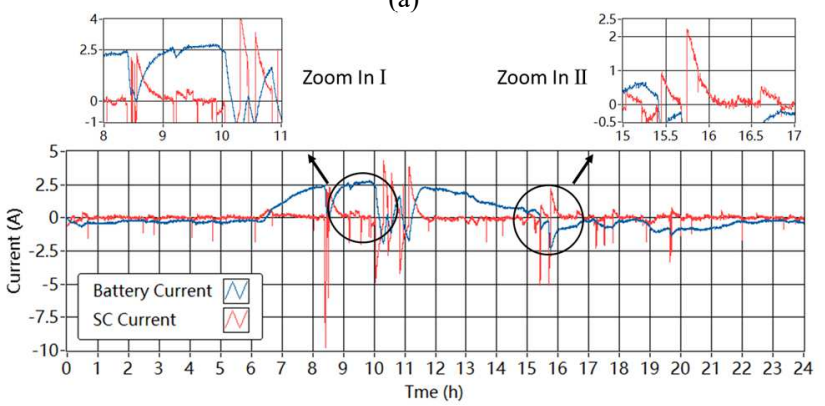

(b)

Fig. 11. Measured currents of battery and SC in the experimental setup with different controllers: (a) LPF controller with fixed $T_{f .}$ (b) LPF controller with variable $T_{f}$.

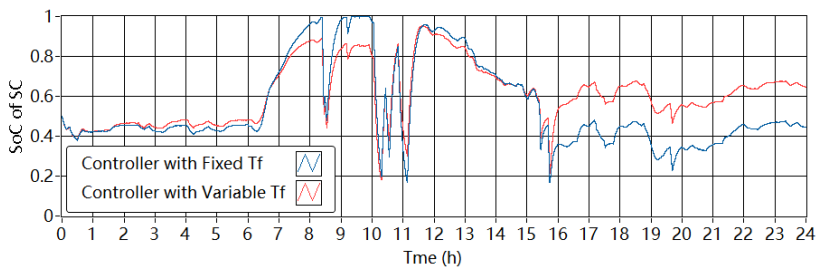

Fig. 12. SoC of SCs in the experimental setup with LPF controllers that utilize a fixed $T_{f}$ and a variable $T_{f}$.

The measured results agree with the simulation results in Section III. Therefore, the power distribution strategy presented in this paper is judged to be effective.

\section{CONCLUSION}

Through the comparison of the LPF controllers that respectively contain a fixed time constant or a variable time constant, the proposed power distribution strategy keeps the $\mathrm{SoC}$ of the SC in a moderate SoC range. Thus, it utilizes the $\mathrm{SC}$ more properly to realize the complementary characteristics of the two energy storage devices and ensures the effective operation of the HESS without the unnecessary enlarging of the SC. An experimental setup with the scaled-down HESS verifies the effectiveness of the proposed power distribution strategy and the simulation results.

\section{REFERENCES}

[1] M. Faisal, M. Hannan, P. J. Ker, A. Hussain, M. Mansur, and F. Blaabjerg, "Review of energy storage system technologies in microgrid applications: Issues and challenges," IEEE Access, vol. 6, pp. 3514335164, May. 2018.

[2] S. Kotra and M. K. Mishra, "Design and stability analysis of dc microgrid with hybrid energy storage system," IEEE Trans. Sustain. Energy, vol. 10, no. 3, pp. 1603-1612, Jul. 2019.

[3] Y. S. Perdana, S. M. Muyeen, A. Al-Durra, H. K. Morales-Paredes, and M. G. Simões, "Direct connection of supercapacitor-battery hybrid storage system to the grid-tied photovoltaic system," IEEE Trans. Sustain. Energy, vol. 10, no. 3, pp. 1370-1379, Jul. 2018.

[4] L. Wai Chong, Y. Wan Wong, R. Kumar Rajkumar, and D. Isa, "Hybrid energy storage systems and control strategies for stand-alone renewable energy power systems," Renewable Sustain. Energy Reviews, vol. 66, pp. 174-189, Aug. 2016

[5] A. Abbassi, M. A. Dami, and M. Jemli, "Statistical characterization of capacity of hybrid energy storage system (HESS) to assimilate the fast pv-wind power generation fluctuations," in Int. Conf. on Adv. Syst. and Electric Technol., 2017.

[6] A. Rosini, A. Bonfiglio, M. Invernizzi, R. Procopio, and P. Serra, "Power management in islanded hybrid diesel-storage microgrids," in 2019 IEEE PES Innovative Smart Grid Technologies Europe (ISGTEurope), 2019.

[7] Q. Zhang and G. Li, "Experimental study on a semi-active batterysupercapacitor hybrid energy storage system for electric vehicle application," IEEE Trans. Power Electron., vol. 35, no. 1, pp. 1014 1021, Jan. 2020.

[8] C. L. Nguyen and H. H. Lee, "Optimization of power dispatch to minimize battery storage capacity in wind farm," in 2013 IEEE Energy Convers. Congr. Expo., 2014.

[9] S. Talari, M. Shafie-khah, G. J. Osorio, J. Aghaei, and J. P. S. Catalao, "Stochastic modelling of renewable energy sources from operators' point-of-view: A survey," Renew. Sustain. Energy Rev., vol. 81, pp. 1953-1965, Jan. 2018.

[10] J. Xiao, L. Bai, F. Li, H. Liang, and C. Wang, "Sizing of energy storage and diesel generators in an isolated microgrid using discrete Fourier transform (DFT)," IEEE Trans. Sustain. Energy, vol. 5, no. 3, pp. 907916, Jul. 2014.

[11] PV Ladder Statistics, Pvoutput.org, 2020. [Online]. Available: https://pvoutput.org/list.jsp?id=14676\&sid=19720

[12] J. Kelly and W. Knottenbelt, "The UK-DALE dataset, domestic appliance-level electricity demand and whole-house demand from five UK homes," Sci. Data, vol. 2, pp. 1-14, Mar. 2015.

[13] X. Lu, Y. Chen, M. Fu, and H. Wang, "Multi-objective optimizationbased real-time control strategy for battery/ultracapacitor hybrid energy management systems," IEEE Access, vol. 7, pp. 11640-11650, 2019.

[14] J. M. Blanes, R. Gutierrez, A. Garrigos, J. L. Liz ' an, and J. M. Cuadrado, "Electric vehicle battery life extension using ultracapacitors and an FPGA controlled interleaved buck-boost converter," IEEE Trans. Power Electron., vol. 28, no. 12, pp. 59405948, Mar. 2013.

[15] RND Programmable DC Power Supply, Datasheet RND 320KD3305P. [Online]. Available: https://www.elfa.se/Web/Downloads/ t/ds/RND\%20320-KD3305P eng tds.pdf

[16] RND Programmable DC Electronic Load, Datasheet RND 320KEL102. [Online]. Available: https://www.elfa.se/Web/Downloads/_t/ds/RND\%20320-KEL102_eng_tds.pdf

[17] RS PRO Lithium Iron Phosphate Battery, Datasheet. [Online]. Available: https://docs.rs-online.com/c8bb/0900766b8172be40.pdf

[18] RND Radial Super Capacitor, Datasheet RND 150HP-2R7J248UNJ50. [Online]. Available: https://www.elfa.se/Web/Downloads/ t/ds/RND\%20150HP-2R7-J248UNJ50 eng tds.pdf

[19] MOSFET, IRL2505PBF - MOSFET N. [Online]. Available: https://www.elfa.se/Web/Downloads/ta/_e/kaIRL2505_Data_E.pdf 